\title{
NUA. NORWICH UNIVERSITY OF ARTS
}

Conf. dr. arh. Remus Hârșan

remusharsan@graphicstudio.ro

NORWICH - MAREA BRITANIE

02/03/2020 - 20/03/2019 


\section{ORAȘUL}

Norwich este un oraș încântător, capitala a districtului Norfolk fiind în același timp capitala a provinciei East Anglia (alături de Suffolk și Cambridgeshire). Fondat în 43 e.n. (cu denumirea Northwic) este definit ca oraș în 1094 după cucerirea normanda ajungând foarte repede - și pentru multa vreme - cel mai mare și important oraș după Londra, loc pe care îl pierde în timpul revoluției industriale. Aflat la $160 \mathrm{~km}$ depărtare de Londra are o populație de $\sim 213.000$ locuitori destul de omogena. Nici marea nu e departe, se ajunge ușor în câteva orășele de coasta extrem de pitorești (mai ales Cromer, renumit pentru crabii săi).

Când ajungi prima oara în Norwich te impresionează cele doua simboluri ale orașului: castelul normand - construit imediat după cucerirea lui William I, și catedrala terminată în 1145 - una din cele mai frumoase din Anglia, a doua ca mărime și ca înălțime din Marea Britanie, după catedrala din Salisbury (Fig. 1). Oricum e foarte mare și îți ia foarte mult timp sa-i descoperi secretele. În afara acestor doua repere majore orașul mai are foarte multe de oferit: Norwich este considerat azi ca fiind orașul medieval cel mai bine conservat din Marea Britanie - ceea ce atrage un număr mare de turiști.

Norwich rămâne una din destinațiile turistice preferate fiind votat de mai multe ori „best place to live in the UK" (2018, 2019, 2020 The Sunday Times), "happiest city to work in

Fig. 1. Catedrala din Norwich. Castelul normand.
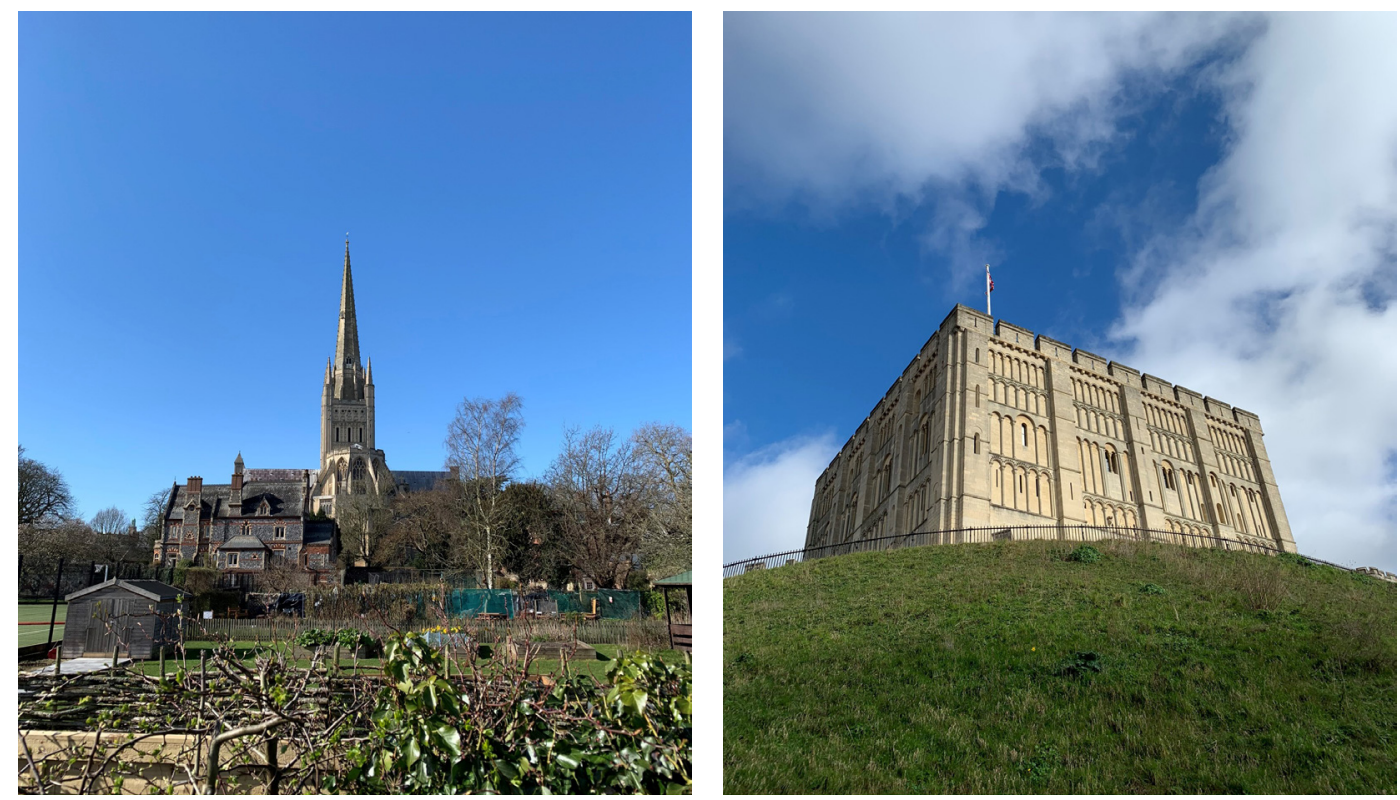
the UK" (2016 The Guardian) sau „best small cities in the world" (2013 The Times). Poate ca la acesta imagine a contribuit lunga tradiție a berăriilor din oraș - se spunea despre Norwich „a pub for every day of the year, and a church for every Sunday ${ }^{3 "}$ și se pare că în 1870 erau înregistrate 780 de berarii. În perioada în care am fost eu mai funcționau însă doar 100.

Orașul, renumit pentru numărul mare de biserici și de baruri, are 2 universități: University of East Anglia (UEA, fondata în 1963, având 18.000 studenți, www.uea.ac.uk) și Norwich University of Arts (NUA, fondată în 1845 având 2.300 studenți, www.nua.ac.uk ). Prima, amplasata în exterior, la marginea orașului - un adevărat microcosmos întins pe 130 ha - cu spatii de învățământ și cercetare, spatii de cazare, spatii pentru biblioteci, etc, este renumită pentru Sainsbury Center for Visual Arts proiectat de Norman Foster în 1974 (Fig. 2). În schimb NUA este amplasată în și prin centrul orașului.
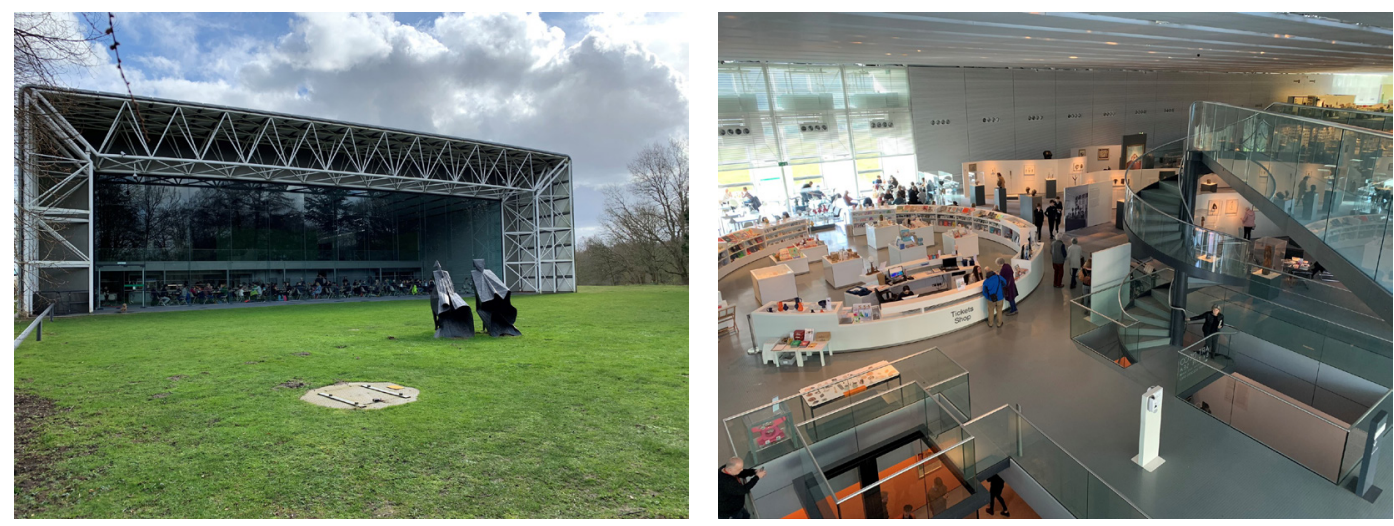

Fig. 2. Universitatea East Anglia: Sainsbury Center for Visual Arts - Norman Foster

\section{2. ȘCOALA}

Norwich University of Arts are 11 corpuri de clădire amplasate în zona centrală a orașului vechi. Universitatea a fost fondată în 1845 sub denumirea de Norwich School of Design. Azi sunt organizate cursuri pentru diverse domenii artistice de la artă, arhitectură, design pentru publicații, comunicare grafică, graphic design, modă, design textil, comunicare și promovare modă, film, animație, video, efecte vizuale, fotografie, imagine, graphic design.

1 "Cel mai fericit oraș din UK în care se poate lucra" (trad. ns.)

2 "Cele mai bune orașe mici din lume" (trad. ns.)

3 „O berărie pentru fiecare zi a anului și o biserică pentru fiecare duminică" (trad. ns.) 
În general, diversele secții au propriile lor spații interferând destul de puțin între ele. Există zone de contact și de suprapunere cum ar fi: sălile mari (amfiteatrul), biblioteca, centrul de editare, zona administrativă, uniunea studenților, spații de expoziții.

În general, clădirile universității sunt remodelări ale unor construcții vechi. Universitatea are - pe lângă spațiile educative - cămine pentru studenți, studiouri foto și de film, ateliere pentru creație vestimentară, spații de expoziție, spații destinate start-upurilor etc. Așa cum spuneam, în Norwich abundă bisericile dar foarte puține dintre ele mai sunt folosite pentru scopul lor inițial. Exista librării, cafenele, spații comerciale amenajate în astfel de biserici, ba chiar am văzut un club pentru escaladă. Una dintre bisericile gotice din proximitate este folosită pentru evenimente ceremoniale (deschiderea cursurilor, acordarea diplomelor, aniversări importante etc.) într-o atmosferă tipic britanică impresionantă (Fig. 3).
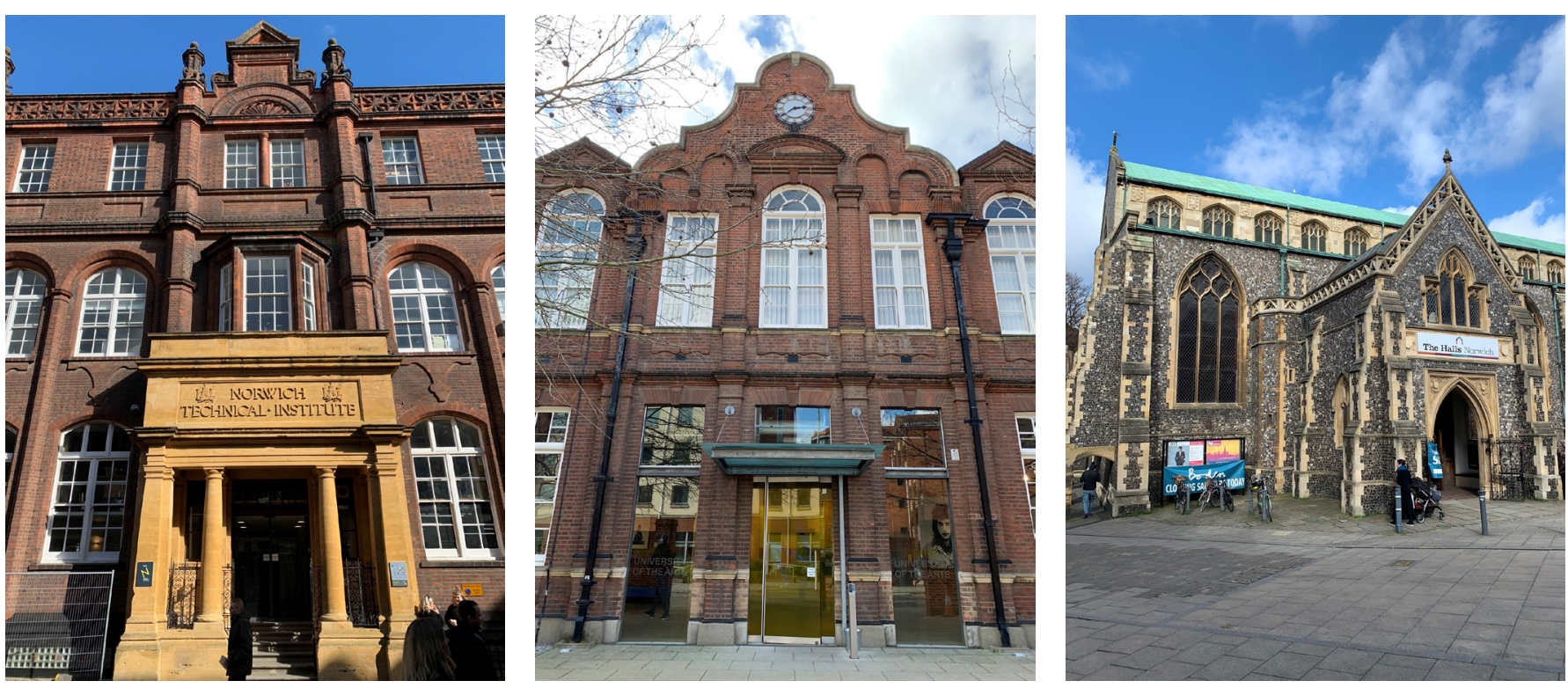

Fig. 3. NUA. Vechiul sediu. Centrul de ceremonii.

Cele 11 clădiri ale universității sunt deci diseminate prin zona centrală dar studenții (și profesorii) care au nevoie să acceseze alte corpuri (biblioteca, amfiteatre, administrația, centrul de editare) traversează - în mod agreabil - centrul istoric, pe nenumăratele străzi pietonale pline de farmec. Clădirea care grupează la parter spații de expoziție și la cele 4 etaje spații pentru start-up oferă spații de lucru, de închiriat pentru tineri - și reprezintă o sursă de venituri suplimentare. 


\section{ATELIERUL}

Școala de arhitectură este adăpostită de o clădire splendidă, amplasată în centrul istoric (Fig.4). Inițial, acest imobil de secol alXIX-lea a fost biblioteca unei biserici invecinate. Dupa ce a fost achizitionat de NUA a fost remodelat și transformat în facultate de arhitectură (la parter și etaj) și facultate de design interior (în demisol). Spațiul universității de arhitectură este organizat în jurul unui imens hol central inundat de lumina zenitală prin luminatoarele acoperișului. Majoritatea spațiilor private sau deschise sunt desfășurate perimetral și orientate către acest hol central.

Spațiul este mobilat cu mese și scaune, rafturi perimetrale. Există monitoare pe suporturi mobile și un ecran de proiecție pentru prezentări. Există o zonă cu calculatoare (cu monitoare noi și mari). Exista un mic laborator foto pentru machete (Fig. 5). De asemenea, un spațiu închis (cu operator) conține imprimante mari pentru formate $\mathrm{A} 0$. Sunt disponibile, de asemenea, mașini de copiat sau de imprimat pentru formate A3. Studenții le pot opera liber pe acestea cu ajutorul cardului (de acces). Există câteva panouri mobile pentru prezentarea proiectelor. Pentru profesori sunt câteva cabinete în care sunt grupați (cam 3-4) și sunt câteva săli de discuții. Nu lipsește un oficiu superdotat (ceai, cafea etc). Atmosfera este liberă, deschisă, extrem de familiară.

Fig. 4. Clădirea Facultății de Arhitectură.
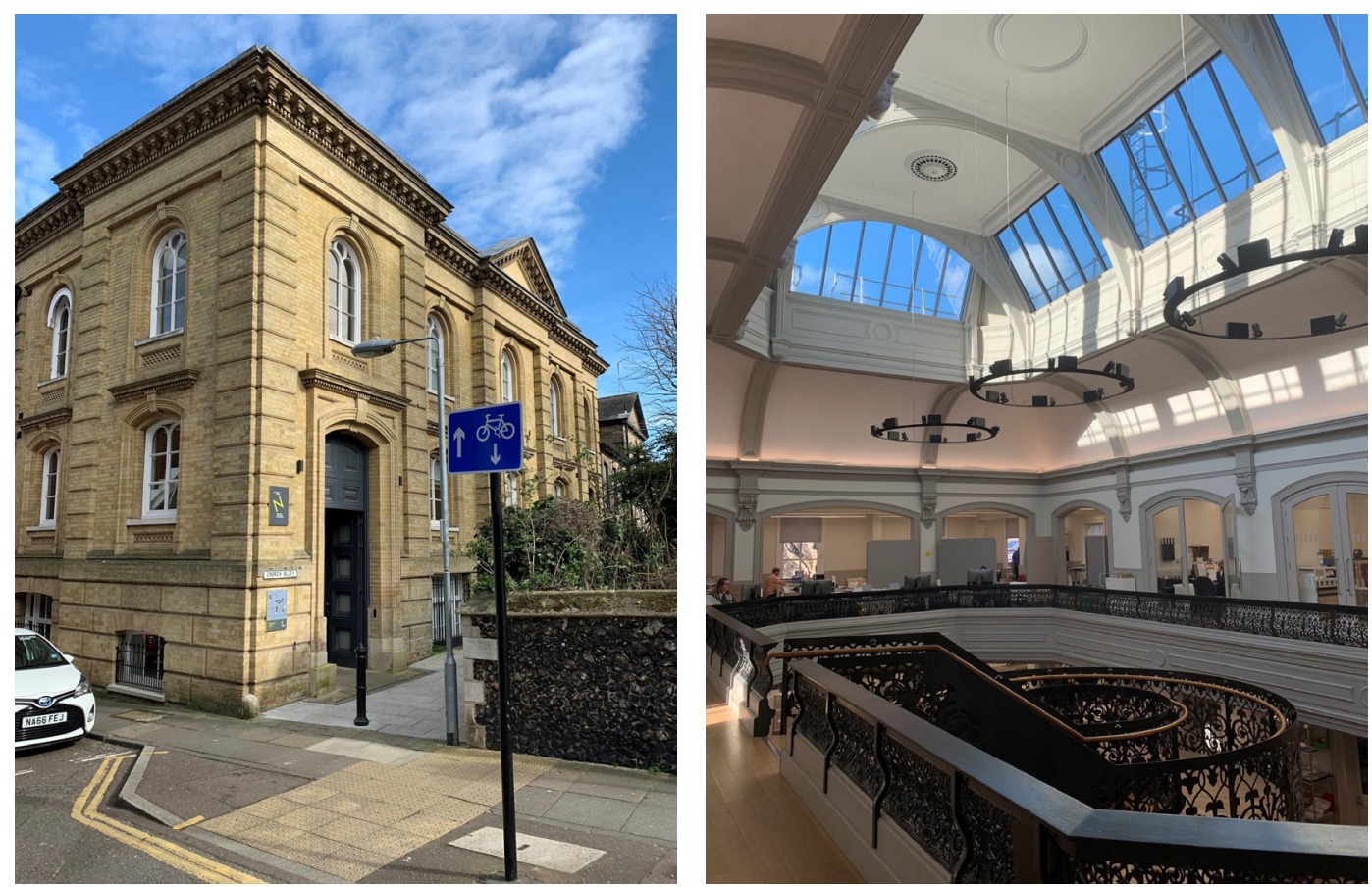
Fig. 5. Studio foto pentru machet.. Atelierul
Facultatea de arhitectură conține cate o grupa de 20 studenți pe trei ani de studii: grupele de anul 1 și anul 2 sunt dispuse la parter în timp ce anul 3 ocupă etajul perimetral. Corpul didactic este comun și susține activitatea prin rotație la cele 3 grupe. Toată activitatea se desfășoară în paralel în acest spațiu zilnic între 9.30 - 17 cu o oră de pauză de masă. Cursurile predate alternează cu activitatea de atelier și cu seminarele. Totuși miercuri era o zi mai lejeră în care studenții aveau liber.

Cursurile erau predate în acel „open space” iar organizarea se facea ad-hoc. Prezentarea era dublata de imagini pe 2-3 monitoare iar cursul era destul de interactiv - studenții erau încurajați să intervină. Tematica era diversă: teorie arhitecturală, istoria arhitecturii, tehnologie, programe de calculator, programe de arhitectură etc. La orice nivel se realizau eseuri la care studenții erau liberi să-și aleagă tema: prima dată se discuta despre temă și profesorul ajuta la definirea câmpului de cercetare; după o săptămâna se discuta scheletul disertației - 2-3 pagini - iar ulterior aveau de finalizat lucrarea pe 20-30 pagini.

Pentru atelier studenții lucrau fie pe hârtie, fie pe calculatoarele școlii, fie pe laptopurile personale. Corecturile se făceau pe baza de programare (aproximativ 30 minute/ student). Se lucra mult pe machete - realizate foarte realist (Fig. 6). În general, grupa se împarte în echipe de 6-7 studenți care realizează un studiu urbanistic, istoric etc.
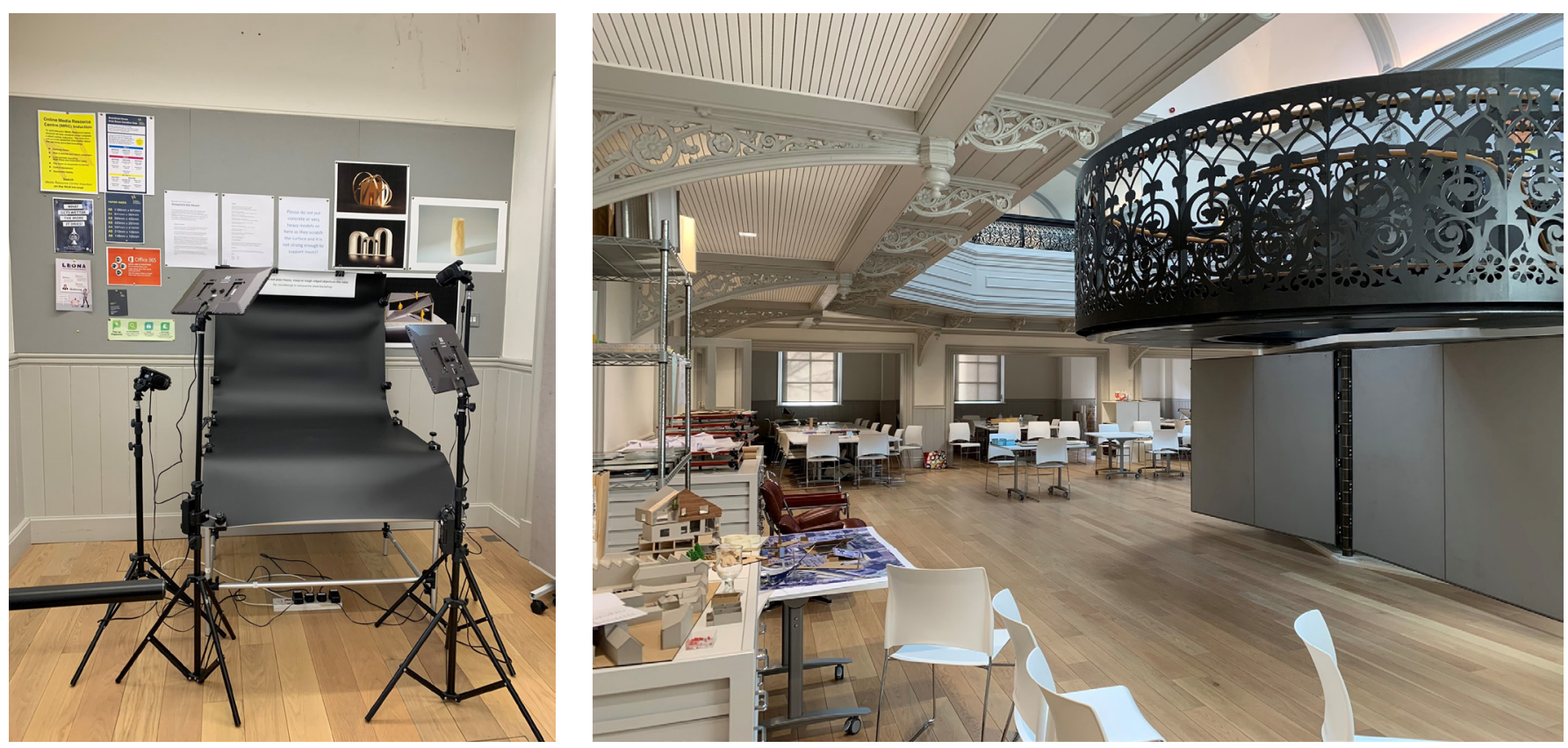
asupra terenului ales și realizează macheta la o scara convenabilă. Prezentările se fac pe panouri mobile iar studenții sunt invitați să participe la dezbateri. Anul 2 avea de realizat propuneri pe două terenuri din Norwich (zone destructurate, centrale, cu vecinătăți valoroase). Anul 3 avea un teren din alt oraș (Hull) care a fost vizitat în prealabil. După realizarea studiilor zonei fiecare student era liber să aleagă un teren și să propună un obiect arhitectural (evident cu propria sa temă).
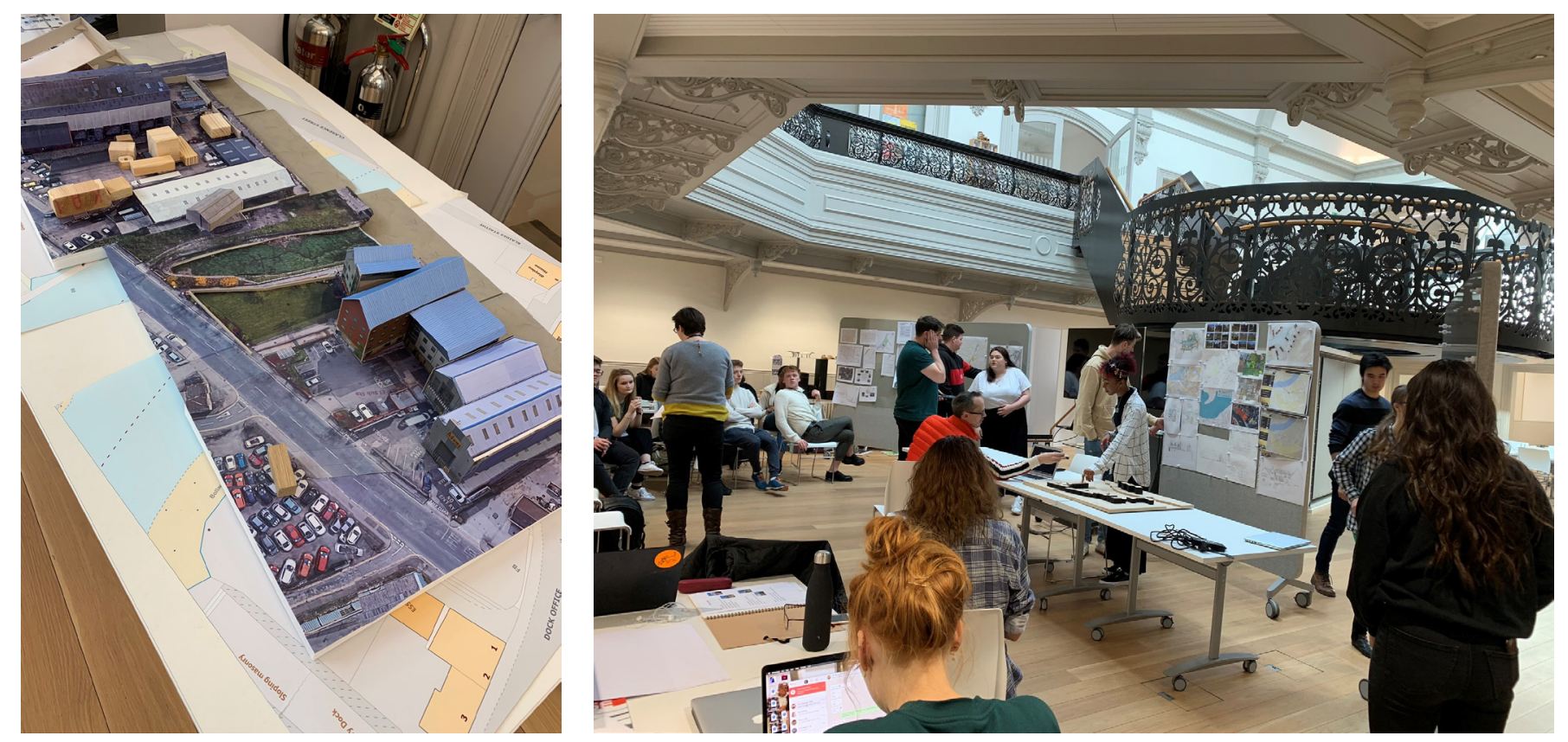

Fig. 6. Machete. Corectura la panou

În alt corp de clădire există un amfiteatru elegant în care se fac prezentări cu un număr mare de participanți. Există obiceiul de a invita birouri mari de arhitectură care să facă prezentări ale lucrărilor în curs - urmate de obicei de workshop-uri în atelier (Fig. 7) (teme legate de proiectul în curs - sau nu). Am asistat la prezentarea unor lucrări (în special V\&A East Museum London) ale biroului irlandez O’Donell \& Tuomey (https:// odonnell-tuomey.ie/). Excursiile de arhitectură cu toată grupa sunt obișnuite. În timpul vizitei mele, anul 2 urma să plece la Berlin - dar pandemia a anulat acest plan. 

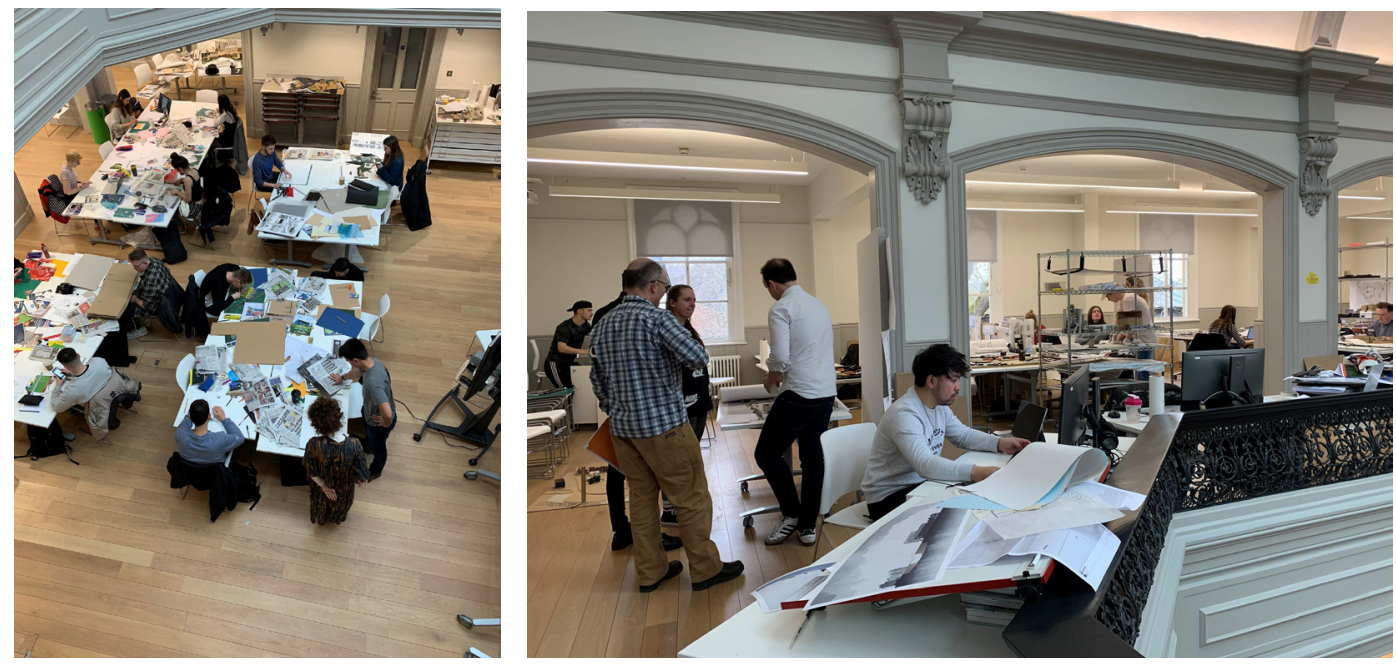

Fig. 7. Workshop cu O’Donell \& Tuomey

\section{CONCLUZII}

Deși nu am participat la evaluarea finala a proiectelor, perioada de timp în care am asistat la activitatea de la NUA mi-a permis să înțeleg și să apreciez modul de lucru, calitatea procesului educațional și nivelul de performanta al scolii. Sper ca lucrurile care m-au impresionat să îmbunătățească performantele mele didactice.

În afara calității deosebite a spațiului și a dotărilor de care beneficiază școala (care presupun investiții consistente) aș menționa câteva observații pe care le-am găsit interesante:

- Modul interactiv de lucru: spațiul deschis favorizează interacțiunea studenților din ani de studiu diferiți;

- Prezentările unor birouri de arhitectură și organizarea de activități în atelier cu membrii acestora;

- Realizarea excursiilor de studiu în diverse locuri cu vizitarea unor lucrări de arhitectură remarcabile;

- Modul deschis (colegial) de prezentare a proiectelor cu discuții extinse între studenți și profesori. 


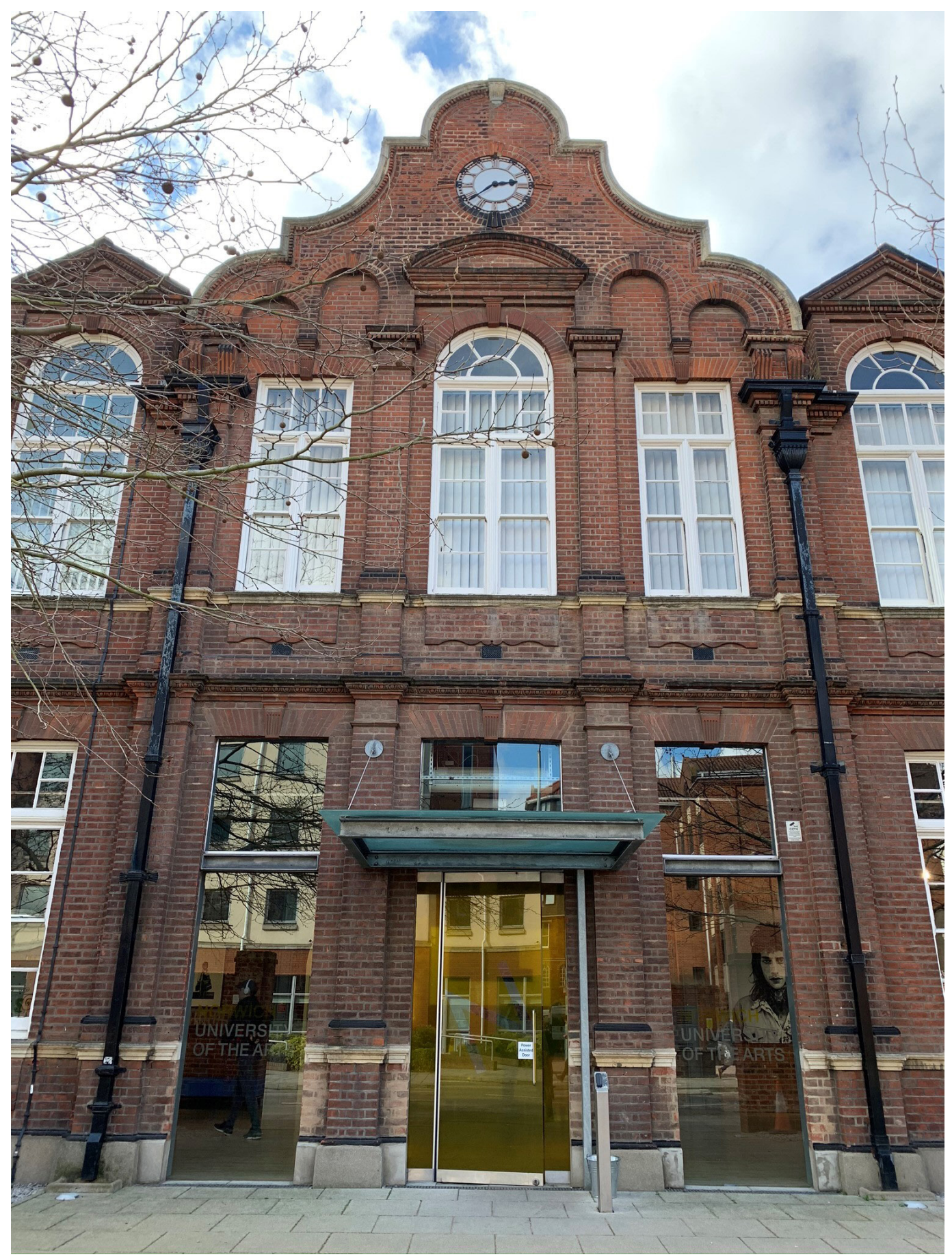

